Article

\title{
Exploring Performance Determinants of China's Cable Operators and OTT Service Providers in the Era of Digital Convergence-From the Perspective of an Industry Platform
}

\author{
Xing Wan ${ }^{1}$, Javier Cenamor ${ }^{2,3}$ (D) and Jing Chen ${ }^{1,4, *}$ \\ 1 School of Business Administration, Nanjing University of Finance and Economics, Nanjing 210023, China; \\ wanxing@nufe.edu.cn \\ 2 Entrepreneurship and Innovation, Luleå University of Technology, 97187 Luleå, Sweden; javcen@ltu.se \\ 3 School of Economics and Management, Lund University, S220 07 Lund, Sweden \\ 4 Rowe School of Business, Dalhousie University, Halifax, NS B3H 4R2, Canada \\ * Correspondence: jchen@dal.ca; Tel.: +86-025-8671-8325
}

Received: 20 September 2017; Accepted: 1 December 2017; Published: 8 December 2017

\begin{abstract}
This paper investigates key determinants of business performance in China's video industry in the era of digital convergence. Specifically, we analyze China's OTT (over-the-top) service providers and cable operators based on the perspective of an industry platform, which acts as the core module of a business ecosystem and is capable of facilitating and coordinating interdependence among different agents. Panel data models are established to empirically explore what factors impact the performance of these two types of players. The findings demonstrate that both platform use and the size of an installed base are crucial for the determinants of the performance of OTT service providers and cable operators. An online video platform can also benefit from an increasing proportion of mobile viewers by implementing a multi-screen strategy. Further, an OTT service provider can profit from the interaction between its installed base and UGC (user-generated content), while cable operators can take advantage of positive feedback between their demand side and supply side.
\end{abstract}

Keywords: digital convergence; industry platform; OTT service providers; cable operators

\section{Introduction}

Since the 1990s, some sectors in the information and communication technology (ICT) industry have been undergoing convergence worldwide. This is an ongoing process ranging from technology convergence to industry convergence [1]. At the stage of industry convergence, firms from previously-distinct industries may compete on a new common playground that changes rapidly, blurring market boundaries and reshaping the market structure of related industries [2,3]. Specifically, the video industry has experienced critical changes in last decade, with a large number of novel technologies and new agents, and shorter life cycles [4]. In this respect, assuring performance sustainability is becoming harder and depends on reaching a solid competitive advantage during the technological battles $[5,6]$. However, these battles are increasingly challenging and firms are not always able to identify how to overtake their competitors, as in previous video display competitions [7]. Thus, new entrants and established firms both face the challenge of identifying how to achieve a competitive advantage.

In this respect, an important question arises: what are the key determinants of business performance for different firms in the video industry? There have been a number of studies of the industry platform competition between established firms and new entrants [8,9]. Industry platforms, which can be products, services, or technologies, serve as foundations upon which a large number of 
agents can make complementary innovations or transactions [10,11]. A firm that provides an industry platform can build a platform-centric ecosystem of businesses, bringing together multiple parties within an industry, primarily users and complementary parties. Here the authors argue that the platform approach is particularly relevant to the research question of business performance in the video industry. Industry convergence usually results in reconfiguration of a value chain, or even a change from value chains to value networks $[12,13]$. Maintaining relationships with partners from previous value chains is not sufficient for a firm to achieve success in a converging industry, but taking a central position in a value network is critical for success [13]. In this sense, market competition in a converging industry is transformed into pursuit of platform leadership, that is, the position of an industry platform [14].

This paper makes two contributions. Firstly, by combining theoretical analysis with empirical research, it helps to explain the complexity of industry convergence. The extant literature on industry convergence generally uses concept frameworks and case studies [15-17], although a few quantitative investigations have focused on measuring industry convergence $[2,18]$. The perspective of an industry platform is useful to understand firm conduct in a converging industry $[19,20]$, while the traditional theoretical framework of industrial organization enables analysis of firm conduct in industries where market boundaries are clear [21]. With this theoretical perspective, the paper analyzes two potential industry platforms in China's converging video industry, i.e., OTT (over the top) service providers and cable operators. Further, it quantitatively explores performance determinants of the two types of businesses in China.

Secondly, this paper contributes to an understanding of the concept of an industry platform. The authors apply the concept in a specific context—China's converging video industry. Regarding OTT service providers and cable operators as potential industry platforms, this paper explores performance determinants for the two types of players. The competition between OTT service providers and cable operators is at its initial stage, with both trying to attract consumers to increase advertising revenues or subscription fees. Therefore, this paper measures performance by revenues, instead of using indicators like profitability. Specifically, the authors make a theoretical analysis of China's OTT service providers and cable operators, and establish empirical models to determine what factors contribute to platform leadership in the era of digital convergence. To the best of our knowledge, this is the first empirical work using the perspective of an industry platform.

The rest of the paper is organized as follows: Section 2 provides a literature review, and hypotheses are proposed in Section 3, Section 4 analyzes OTT service providers and cable operators; empirical analysis is described in Section 5; and Section 6 concludes the paper.

\section{Literature Review}

The converging video industry is increasingly colonized by established traditional and Internet intermediaries that compete for platform leadership, and become an ecosystem of innovation in which third parties are encouraged to develop complementary products and services [22,23]. The digitalization of the video industry has blurred the traditional entry barriers. Not only small firms, but also users, are able to reach unprecedentedly large audiences and have become popular content creators, like YouTubers [24].

In a converging industry, cross-boundary offerings often require cooperation among heterogeneous actors. A platform can act as an ecosystem aggregator capable of bringing together complementary parties and facilitating their cooperation [20]. Further, pervasive digital technologies have heightened the role of the platform and made it the central focus of market innovation $[19,20]$. To harness the convergence made possible by pervasive digital technologies, firms now innovate by creating platforms rather than single products [19]. In fact, some firms have achieved a dominant position in this converging market by providing a platform for market participants. Such a platform is neither a product platform within an organization, nor a platform for a specific purpose, but an industry platform that acts as the hub of a whole ecosystem of businesses $[10,25]$. 
An industry platform can be a foundation technology or service essential for a broader, interdependent ecosystem of businesses [22]. As a core module of an ecosystem, an industry platform both provides the core functionality of an ecosystem and implicitly or explicitly establishes the rules of the ecosystem that govern interactions between different parties [26]. Specifically, a platform owner can regulate access through the platform and interactions around it through nuanced combinations of legal, technological, informational, and other instruments [27]. Generally, an industry platform can facilitate and coordinate interdependencies within and across multiple sets of actors [28,29]. The interdependencies can be interactions among the same group of agents, between different groups of agents on the platform, or between the platform owner and agents on it.

In the first case, E-communities or social networking websites are types of platforms that can facilitate interaction through electronic word of mouth (EWOM). Being aware of the increasing importance and power of the demand side, some platform providers aim to exploit collective intelligence and user innovation [30,31].

In the second case, a platform usually provides a two or multi-sided market where different agents interact with each other [32]. A two/multi-sided market is characterized by cross-side network effects $[33,34]$. The network effects arise when adding an additional participant to one side of a two-sided market increases or decreases utility for participants on the other side [35]. A platform can internalize cross-side network effects by aggregating a large network of both sellers and buyers and providing matching and value-added services for the two parties [36]. As a result of its mediating role, this type of platforms usually has the advantage of reducing transaction costs for both the demand side and the supply side, as compared with other trade or interaction mechanisms, such as markets [37]. In this sense, a platform firm may manage a marketplace, and its mediating role partly replaces the function of the market.

In the third case, an industry platform can transform and exploit its relationships with other agents in a platform ecosystem. A platform owner can change the traditional linear value chain into a triangular or multi-sided platform shape [32]. Platform owners have established "coopetitive" relationships with supply-side users. On the one hand, platforms owners cooperate with supply-side users to co-create value, and on the other hand, they become competitors for value capture. A platform owner can also reshape its relationships with the demand side by allowing and enabling various participation levels from end users [38].

The rapidly changing context is pushing managers to adapt their business models when opportunities or threats arise in order to enter or survive [39,40]. With properly-designed business models, a platform owner can exploit relationships with other agents in multiple ways. A platform owner can enhance platform adoption by formalizing and institutionalizing its interaction with supply-side or demand-side agents, such as logistical and financial infrastructure for supply-side users and recommendations systems for end users. Further, a platform owner can move into a new market by leveraging its installed base in an established market [41,42]. For example, Apple increased the attractiveness of the iPhone by leveraging its installed base of iTunes, as iTunes consumers can use an iTunes account to manage their iPhone and purchase applications, as well as music.

\section{Hypotheses}

\subsection{Platform Participation and Engagement}

The switchover from analog TV to digital TV facilitates the active behaviour of TV watchers [43]. With technologies like VOD and time-shift TV, watchers enjoy more freedom in content and time selection [44]. However, China's TV audience has remained content consumers to such an extent that they neither create content nor interact with other viewers. This means that no direct network effects exist among viewers of digital TV. Additionally, cable operators have not changed their business models fundamentally. In the analog era, China's cable operators relied on fees charged for basic and premium channels. In the digital era, they still heavily depend on fees from customers rather than 
advertisers. Previous empirical research has demonstrated the positive linear relationship between the performance of a cable operator and the number of its basic-tier or premium-tier subscribers in the digital age [43] and the analog era [45,46]. Therefore, we postulate the following hypotheses:

Hypothesis 1a (H1a). The performance of a cable operator is positively correlated with the number of digital TV subscribers.

Hypothesis $\mathbf{1 b} \mathbf{b} \mathbf{H 1 b})$. The performance of a cable operator is positively correlated with the number of pay TV subscribers.

In the digital era, cable operators can improve their service quality by means of deploying digital technologies; specifically, digital technologies enable them to offer more channels at lower costs. The availability of complementary products has a positive impact on the adoption of products or services [9]. Content is complementary to service provided by a cable operator, which can benefit from content variety [47]. In the context of China's TV industry, adding channels can contribute to a cable operator's revenues in two ways. First, cable operators can raise the subscription prices after the switchover to digital TV. It is common practice for China's cable operators to raise subscription fees when they offer more channels in a basic tier after the digital transition [43]. Second, cable operators can expand their installed base with more channels offered. More channels may attract more subscriptions from viewers who recognize value of diverse content. Therefore, we posit the following hypothesis:

Hypothesis 2 (H2). The performance of a cable operator is positively correlated with the number of available channels.

Although most users can watch video programs for free on China's OTT service providers, this does not imply that the value of a user is zero. An OTT service provider needs to take into account direct network effects between audiences, and cross-side network effects between audiences and advertisers when calculating the value of an audience [48]. Direct network effects arise when adding an additional viewer increases utility for other viewers. In this way, users can attract and retain more users. Cross-side network effects arise when adding an additional viewer to one side of a platform increases the utility for advertisers on the other side [49]. In this sense, additional viewers can attract and retain more advertisers. Under direct or cross-network effects, the utility function for viewers or advertisers usually takes a linear form of the number of viewers either in analytical models $[49,50]$ or empirical models [51,52]. The value of an online video (platform), which is the sum of utility for all viewers and advertisers is, therefore, correlated with the square of the number of its viewers, according to Metcalfe's Law [53]. Thus, we posit the following hypothesis:

Hypothesis 3 (H3). The performance of an OTT service provider is positively correlated with the square of the number of viewers.

It is platform engagement that represents the frequency of users' interaction with a platform [54]. If user multi-homing behaviour is common, the number of active users on a platform is more important than its installed base, and so platforms focus their competition on active users rather than registered users. In the context of the video industry, users have changed their roles from viewers to participants while the video industry itself is moving from broadcasting to connectivity [44]. In this way, indicators of engagement are highlighted in the digital era. For example, fees for Internet advertising are based more on indicators like page views than on the number of registered users. Therefore, we present the following hypothesis:

Hypothesis $4 \mathbf{~ ( H 4 ) . ~ T h e ~ p e r f o r m a n c e ~ o f ~ a n ~ O T T ~ s e r v i c e ~ p r o v i d e r ~ i s ~ p o s i t i v e l y ~ c o r r e l a t e d ~ w i t h ~ t h e ~ n u m b e r ~ o f ~}$ page views. 
The users' role is not restricted to platform participation, but can also be extended to platform contribution and innovation [55]. Enabled by information technologies, users are not only viewers and consumers, but also reviewers and producers in the interactive media industry [56]. User-generated content (UGC) can be one of key components of the multi-sided platform strategies of an OTT service provider. For example, US-based YouTube enjoys a self-producing, self-consuming cycle by focusing on a UGC strategy [57]. UGC and short videos are particularly suitable for online platforms because smaller screens reduce the risks of bad video quality and limited network capacity. Firms can, thus, take advantage of users as producers and innovators from content creation and enhanced platform participation [58]. Therefore, we present the following hypothesis:

Hypothesis 5 (H5). The performance of an OTT service provider is positively correlated with the amount of UGC.

Enabled by cloud computing, viewers can use their accounts to enjoy a seamless watching experience across devices [59]. Meanwhile, China has, in recent years, witnessed an increasing penetration of mobile devices, fuelled by decreasing costs for devices and bandwidth. Thus, it is both convenient and affordable for China's viewers to watch video on their mobile devices. This stimulates two additional aspects of demand for content on OTT service providers. First, viewers who do not have wired access to the Internet may find that video applications offered by OTT service providers can fulfill their unsatisfied demand. Second, viewers whose content consumption demand cannot be satisfied by desktop computers may regard mobile video as a complementary service. In the former case, mobile availability of video programs can expand the installed base of an OTT service provider. In the latter case, mobile availability can enhance platform engagement of an OTT service provider. Therefore, we present the following hypothesis:

Hypothesis 6 (H6). The performance of an OTT service provider is positively correlated with the proportion of mobile users.

\subsection{Interaction between the Demand Side and the Supply Side}

A cable operator can be regarded as a platform mediating interactions between viewers and channel providers. Cross-network effects exist between TV watchers and content providers [60]. Such effects can produce mutually-reinforcing positive feedback between the two sides $[9,61]$, that is, more viewers are likely to attract more channel providers, and more channels will draw more subscribers. Recognizing cross-network effects, China's cable operators try to internalize these externalities between the two sides by properly pricing and improving customer services [43]. For example, China's cable operators usually give subscribers digital set-top boxes (STBs) for free to increase the installed base, which helps to attract more channels, which in turn expands the size of viewership. Thus, we present the following hypothesis:

Hypothesis $7 \mathbf{~ ( H 7 ) . ~ T h e ~ p e r f o r m a n c e ~ o f ~ a ~ c a b l e ~ o p e r a t o r ~ i s ~ p o s i t i v e l y ~ c o r r e l a t e d ~ w i t h ~ t h e ~ i n t e r a c t i o n ~ t e r m ~}$ between the number of digital subscribers and the number of available channels.

Based on the IT fusion view proposed by El Sawy [62], IT is not only immersed in, but also fused with, the business environment. In this sense, content websites emphasize content-related and IT-enabled social experience rather than the content itself [38]. This means that content websites focus their business models on a hybrid between "content provider" and "social community". UGC represents a higher level of participation of users in an online social community. UGC publishers are more likely to play the role of a group leader in an online community, having a significant impact on the behaviour of community members, such as video watching or subscription [38]. An OTT service provider can design an IT system to take advantage of the interaction between UGC and participation and engagement of viewers and, in fact, UGC is one of the key components in the digital business 
strategies of China's OTT service providers. To differentiate from traditional media, some of China's OTT service providers intentionally encourage UGC to increase platform participation and loyalty [63]. Therefore, we present the following hypotheses:

Hypothesis 8a (H8a). The performance of an OTT service provider is positively correlated with the interaction term between the amount of UGC and the number of viewers.

Hypothesis $\mathbf{8 b} \mathbf{( H 8 b )}$. The performance of an OTT service provider is positively correlated with the interaction term between the amount of UGC and the number of page views.

Our hypotheses are summarized in Figure 1.

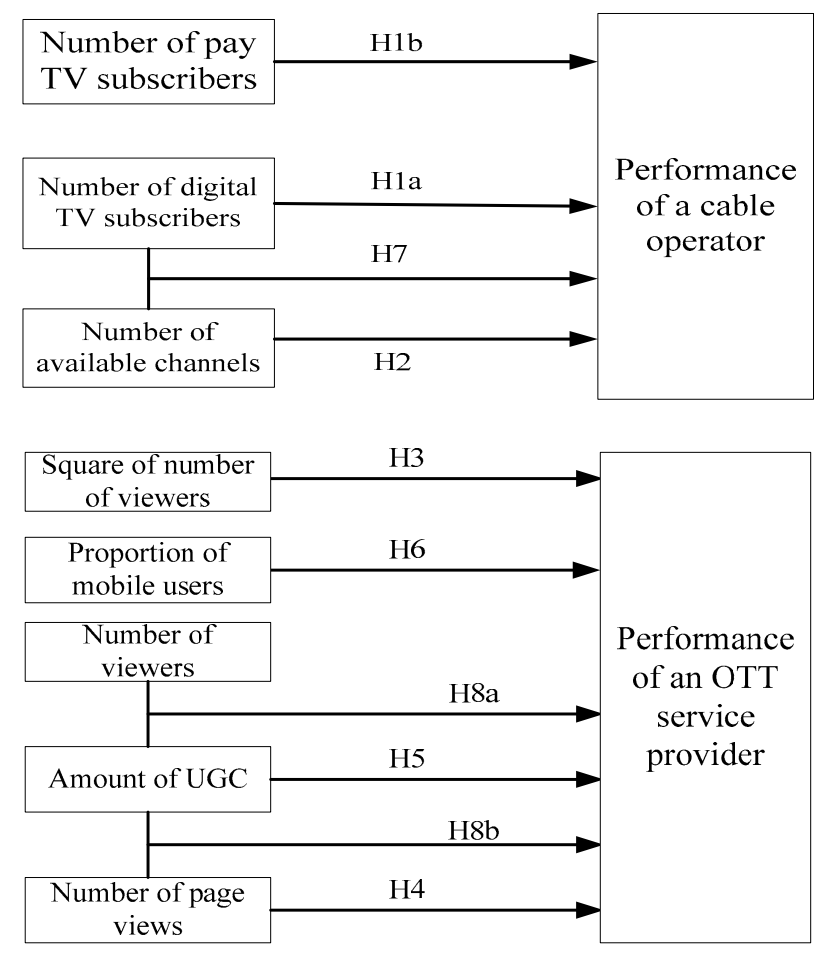

Figure 1. Summary of hypotheses.

\section{Analysis of China's Cable Operators and OTT Service Providers}

China's video industry represents a large and growing sector determined by market forces and remarkable regulation policies. In this respect, China's video industry is undergoing digital convergence, featuring the entry of OTT service providers and the transformation of the traditional TV sector. The remarkable rise of China's Internet video sector has dwarfed the slow growth of its traditional TV sector, which consists of TV stations and network operators. From 2008 to 2016, China's OTT service sector registered an annual rise of $13.20 \%$ in the number of users [64]. Even so, the traditional sector, which controls quality content and network access, still dominates the video market in terms of advertising revenues and subscription fees. Thus, it is difficult to determine which players will achieve leadership in the converging video industry.

\subsection{Cable Operators}

\subsubsection{Overview}

Cable TV has dominated China's official transition to digital TV, since the State Administration of Radio, Film, and TV (SARFT) has implemented a policy giving priority to digitalization of cable TV. 
Further, China's government has implemented the policy of "Uniform Transition" for digital cable TV, which has greatly accelerated the adoption of digital cable TV [43]. Thanks to the large size of audiences prior to the digital transition, cable operators possessed a huge installed base of digital subscribers after the transition. Digital convergence therefore offers a good opportunity for China's cable operators to provide value-added video services or even triple-play services; they regard digital TV transition as an opportunity to transform themselves from administration-oriented to market-oriented players.

Subject to regulations by the SARFT, China's cable operators are local monopolies controlled by local governments at various levels. In comparison with China's telecom operators which compete in nationwide markets, China's cable operators lack business resources and market experience [17]. A majority are short of the funds necessary to upgrade their cable networks from mono-directional to bidirectional networks. Several cable operators that have accomplished network upgrades find it difficult to challenge the position of telecom operators in local broadband or voice markets [43]. Therefore, a majority of China's cable operators have concentrated their efforts on value-added video services, like video-on-demand (VOD), rather than triple-play services.

In the digital era, cable operators earn revenues mainly from two sources: fees for digital TV access and fees for value-added services. Since the transition from analog TV to digital TV, cable operators have universally raised the prices for TV access, using the excuse of the higher cost of delivering digital TV. Although value-added services have gradually enhanced their contribution to the total revenues of cable operators since the digital transition, China's cable operators still rely heavily on these access fees. According to an annual financial report from Jiangsu Cable, the largest cable company in China, digital access accounted for $71.1 \%$ of its revenues from individual customers in 2016, while broadband service accounted for $16.9 \%$ and value-added service, like VOD, $12.0 \%$, respectively.

\subsubsection{Cable Operators as a Potential Industry Platform}

With the digital transition, China's cable operators have extended their role from a content distributor to an intermediary between content/service providers and audiences. In the analog era, China's cable operators acted as a pipeline of content. They neither understood nor controlled audience demand, as STBs were not introduced into the market until the digital switchover. In the digital era, China's cable operators have made efforts to transform themselves from a dumb pipeline to a proactive platform.

On the demand side, China's cable operators have paid more attention to customer services. Some have established customer service institutions to improve customers' experiences, including call centers and community managers. Beyond traditional customer services, cable operators can make use of digital technologies to interact with customers. STBs constitute a technology foundation in the business ecosystem of a cable operator. On the one hand, cable operators can use STBs to precisely control which customers have access to which services, so as to avoid the free-ride behavior that was rampant in the analog era. On the other hand, usage data recorded by and stored in STBs better allow cable operators to know about their demand. A cable operator can have detailed information for each individual customer, and manage its customers and market its products more effectively and efficiently.

On the supply side, China's cable operators have tried to diversify content sources and provide value-added services. In the digital era, they have offered an increasing number of free and premium channels, such as high-definition TV channels. In addition to channels, cable operators provided free and paid content, like films, that are accumulated by cable operators themselves. In this way, they have changed their role from traditional content transmission to content aggregation. Cable operators also attract customers with value-added services, comprising internal and external services. Cable operators, themselves, can provide video value-added services such as VOD and time-shift TV, and they can cooperate with third parties who offer services on their platforms. For example, Hangzhou Huashu, a cable operator in Zhejiang Province, has cooperated with Alibaba-China's largest electronic business corporation—on digital TV-based electronic commerce. 
In a word, China's cable operators, especially the larger ones, have gradually evolved into a smart intermediary, not only between content providers and aggregators and audiences, but also between service providers and end users. They make use of digital technologies to better coordinate relationships between content/service providers and audiences. By leveraging the installed base of digital TV and cooperating with third parties, they can even move into new markets.

\subsection{OTT Service Providers}

\subsubsection{Overview}

With the increasing penetration of broadband, China has, for years, witnessed a rising number of Internet video viewers. The country registered 513.91 million online video viewers by the end of June 2016, accounting for $72.4 \%$ of its online population [64]. Among the 513.91 million online watchers, $85.7 \%$ of users chose to watch video on smart phones. Rich video content has also drawn audiences from traditional media to OTT service providers, which are subject to less content regulation than TV stations. The market of China's OTT service providers is more concentrated than that of cable operators. As a result of exclusive franchises granted by local governments, the market of China's cable operators features local monopoly and national fragmentation [65]. By contrast, China's OTT service providers have to compete with one another for a nationwide audience. The fierce competition had eliminated more than $90 \%$ of China's OTT service providers by 2012 , with only twenty to thirty surviving [63]. By 2013, each of the top 15 OTT service providers achieved a penetration level above $10 \%$. The top three-Youku Tudou, Aqiyi PPS, and Tencent Video-had a penetration of $70.4 \%, 63.8 \%$, and $43.9 \%$, respectively [63].

Despite the rapid growth and increasing concentration of China's online video industry, however, most OTT service providers have not yet made profits. The losses can be ascribed to their high costs and limited sources of revenues. For one thing, China's OTT service providers have to pay much higher prices for bandwidth than their western counterparts [57]. At the same time, China's OTT service providers still rely heavily on advertising revenues, although they have tried to expand their revenue sources. According to a report by iResearch, advertising revenues accounted for $55.2 \%$ in total revenues of OTT service providers in the second quarter of 2016, while subscription fees reached $18.2 \%$ and others sources, including copyright distribution and derivatives, reached $26.6 \%$. Table 1 compares China's cable operators and OTT service providers.

Table 1. Comparison of China's cable operators and OTT service providers.

\begin{tabular}{ccc}
\hline & Cable Operators & OTT Service Providers \\
\hline Orientation & $\begin{array}{c}\text { Both administrative and } \\
\text { market orientation }\end{array}$ & Market orientation \\
\hline $\begin{array}{c}\text { Ownership and } \\
\text { control right }\end{array}$ & $\begin{array}{c}\text { State owned, and controlled by } \\
\text { local governments }\end{array}$ & $\begin{array}{c}\text { Most OTT service providers } \\
\text { privately owned }\end{array}$ \\
\hline Market structure & $\begin{array}{c}\text { Fragmented in cities and counties, with } \\
\text { disconnected networks }\end{array}$ & $\begin{array}{c}\text { Dozens of OTT service providers; less } \\
\text { than 20 with national influence }\end{array}$ \\
\hline $\begin{array}{c}\text { Content-related } \\
\text { business }\end{array}$ & $\begin{array}{c}\text { Content transmission, aggregation and } \\
\text { value-added content services like VOD }\end{array}$ & $\begin{array}{c}\text { Online content production, } \\
\text { aggregation and broadcasting }\end{array}$ \\
\hline $\begin{array}{c}\text { Major source of } \\
\text { revenues }\end{array}$ & $\begin{array}{c}\text { Subscription fees, and revenues from } \\
\text { value-added digital TV services }\end{array}$ & Advertising revenues \\
\hline
\end{tabular}

\subsubsection{OTT Service Providers as a Potential Industry Platform}

Online video platforms have designed IT-enabled demand-side strategies to turn their audience into consumers, marketers, and producers, and this may give them competitive advantages over traditional media in the converging video industry. By means of information technologies and institutional arrangements, China's leading OTT service providers have established an online community. The online community embedded in an online video platform greatly magnifies audience 
interaction in terms of both depth and breadth [66]. The interaction includes real-time communication among audience members, and audience members' lagged reactions to messages from other members or generated by the online video platform's automated information system. A majority of China's OTT service providers collect data on audience behavior and opinion, and most of this data is intentionally available to the public to stimulate user engagement and viewership. For example, Youku, one of China's leading OTT service providers, allows its audience members to interact on any specific content they watch or interact with their friends in Youku's online community. Furthermore, Youku users can now connect their Youku accounts to other social media, such as QQ and Weibo, which makes it easier to share information, recommendations, and opinions about videos through the members' external social networks. Some of China's OTT service providers, such as 6Rooms and www.56.com, go further in developing online communities by supporting social networking based on live online shows and real-life videos created by individuals.

In addition to online communities, some of China's video platforms encourage and support UGC, for which the cost is much lower than for professionally-generated content (PGC). With the rise of UGC, the boundary between consumers and producers is becoming blurred. www.tudou.com, for example, which has the slogan "Everyone can be a director of life," has always attached importance to UGC. This firm has taken measures to increase the amount of UGC and improve its quality, including training amateurs and connecting amateurs with professionals.

China's OTT service providers are fulfilling the "anywhere" promise of video distribution. This is a result of the combined effect of the proliferation of portable media devices and the mobile apps launched by these OTT service providers. China's leading OTT service providers have all launched mobile apps, which have greatly facilitated the growth of the mobile Internet video market. Mobile Internet audiences accounted for $91.80 \%$ of Internet video audiences in 2016. These leading OTT service providers, such as Youku and Iqiyi, provide multi-screen and cross-platform services with diverse features and high-quality experience. As a result, mobile users of OTT service providers can enjoy seamless switching between multiple screens, and access abundant content specifically tailored to portable devices. They also enjoy the convenience of content compatibility on different operating systems like Android and iOS.

In addition to the multi-screen strategy, China's OTT service providers have been making efforts to diversify content sources, including UGC, PGC, content purchased from studios, and self-produced content. Furthermore, Internet videos are more flexible than TV programs in terms of length and format. For the purpose of linear broadcasting, TV programs are broadcast in fixed time slots in a defined format. Online video content is not subject to time or format constraints, and this unleashes the potential creativity of both individual amateurs and professional organizations.

China's leading OTT service providers are different from players in the traditional TV sector in the following two aspects. First, OTT service providers provide better matching services for viewers and content suppliers than cable operators. The online video platforms provide several resources to help users find content. Users can search with keywords, browse across channels, and check the top video programs by channel. Once audience members have identified their favorite videos, they can examine other videos identified as similar by the OTT service providers. Some leading OTT service providers have given registered users tools to customize their home screens to render favored sources of content immediately available. With the aforementioned matching services, online video platforms can satisfy the heterogeneous needs of audiences better than traditional TV media. These heterogeneous needs, in turn, greatly promote consumption of niche content and bring the benefit of the long-tail effect to online video platforms.

Second, China's leading OTT service providers have gradually become a combination of media and social-community platforms. Consumers' demand for content consumption and desire for social experience complement each other [67]. Social experience in virtual communities can increase an audience member's interest in consuming more content, while content consumption can expand the potential scope of social interactions. Some OTT service providers have devised strategies to 
explore and exploit synergy between the two types of sub-platforms. For instance, Ku6.com has now repositioned itself as a video-based social networking site.

\section{Empirical Analysis}

\subsection{Data and Variables}

\subsubsection{Cable Operators}

China's cable operators are invested in, and controlled by, governments at various levels, including the provincial, city, and county levels [43]. This paper uses provincial-level cable operators as the unit of empirical analysis due to data availability. Using this aggregate data can also be justified by the fact that China's cable operators have accomplished horizontal integration in many provinces, as ordered by the SARFT, and city and county cable operators have become branches of provincial cable operators. Here, the selected sample consists of 24 provincial cable operators, using data from 2007 to 2014 as the sample. The 24 provinces are Anhui, Fujian, Gansu, Guangdong, Guangxi, Guizhou, Hainan, Hebei, Henan, Heilongjiang, Hubei, Hunan, Jilin, Jiangsu, Jiangxi, Liaoning, Inner Mongolia, Ningxia, Shandong, Shanxi, Shaanxi, Sichuan, Yunnan, and Zhejiang. Provinces like Tibet are excluded because the available data is incomplete. The chosen sample period is 2007 to 2014, because China started the transition to digital TV in 2006. Data was collected from the China Statistics Yearbook, China Social Statistics Yearbook, and China TV Rating Yearbook.

The dependent variable Netrev $_{i t}$ denotes the revenues of the $i$ th province's cable operators in the $t$ th year. This variable captures the performance of China's cable operators, whose revenues depend on network service fees. The independent variable Digcov $_{i t}$ and Paycov $_{i t}$ measure the amount of digital TV and pay TV subscribers respectively in the $i$ th province in the $t$ th year. Digcov $i t$ captures the installed base of digital cable TV in the era of digital convergence, and Paycov ${ }_{i t}$ represents the installed base of pay TV, including HDTV and VOD. The variable Numchan ${ }_{i t}$ measures the average number of basic tier channels received by every household in the $i$ th province in the $t$ th year. It captures the feature of program supply on the platform of cable operators. The study controls for region-specific characteristics of cable operators. The control variable Netlen ${ }_{i t}$ denotes the total length of backbone cable networks in the $i$ th province in the $t$ th year. Netlen $n_{i t}$ represents the supply of network infrastructure by cable operators. The control variable View $w_{i t}$ denotes average TV watching minutes per day in the $i$ th province in the $t$ th year, which captures the popularity of services provided by cable operators. The control variable Broadpen $_{i t}$ reflects household broadband penetration in the $i$ th province in the $t$ th year. Broadpen ${ }_{i t}$ is included to capture the impact of Internet access on cable operators. Region dummies are included as proxies of unobserved differences across provinces. Table 2 summarizes the statistics and correlations of key variables, and lists data sources. Although the majority of the correlation coefficients have moderate values, variance inflation factors (VIFs) were calculated for all the variables and none of them was higher than 2. As values up to 10 are permitted [68], multicollinearity is not a problem in this study.

Table 2. Descriptive statistics and correlations of variables for cable operators.

\begin{tabular}{lccccccccccc}
\hline & Mean & SD & Min & Max & $\mathbf{1}$ & $\mathbf{2}$ & $\mathbf{3}$ & $\mathbf{4}$ & $\mathbf{5}$ & $\mathbf{6}$ & Sources \\
\hline 1. LnDigcov & 14.47 & 0.98 & 11.08 & 16.49 & 1.00 & & & & & & 1 \\
2. Ln Paycov & 11.65 & 2.12 & 3.91 & 14.91 & 0.68 & 1.00 & & & & & 1 \\
3. LnNumchan & 3.54 & 0.29 & 2.40 & 4.19 & 0.55 & 0.38 & 1.00 & & & & 1 \\
4. LnNetlen & 11.37 & 0.98 & 7.68 & 13.03 & 0.54 & 0.58 & 0.08 & 1.00 & & & 1 \\
5. Ln View & 5.05 & 0.11 & 4.82 & 5.33 & 0.14 & -0.06 & 0.03 & 0.28 & 1.00 & & 2 \\
6. Broadpen (\%) & 30.02 & 15.55 & 7.02 & 79.09 & 0.69 & 0.46 & 0.58 & 0.33 & 0.17 & 1.00 & 3 \\
\hline
\end{tabular}

Sources: INFOBANK data base. 1: China Social Statistics Yearbook; 2: China TV Rating Yearbook; and 3: China Statistics Yearbook. 


\subsubsection{OTT Service Providers}

The number of China's OTT service providers dropped from more than 300 in 2006 to around 20 in 2012 as a result of fierce competition [63]. This paper selects market incumbents from 2011 to 2014 as the sample, to represent viable OTT service providers and meet the purpose of this paper to explore performance determinants. In light of data availability, the final data set includes annual data on China's 17OTT service providers: Youku Tudou, Iqiyi, Tencent Video, Sohu Video, LeTV, PPTV, Xunlei Kankan, 360 Video, Sina Video, www.fun.tv, www.ku6.com, v.ifeng.com, www.baofeng.com, www.56.com, v.163.com, CNTV, and www.joy.cn. According to statistics released by iResearch, the 17 OTT service providers accounted for $98.20 \%$ of the advertising revenues of China's online video sector in 2013. On average, each of these 17 OTT service providers covered $23.14 \%$ of China's online video audiences in 2013 [63]. The data on the OTT service providers was collected from three sources: the annual reports of CNNIC on online video, the annual reports on online video released by iResearch (www.iresearch.com) and Yiguan (www.Enfodesk.com).

The dependent variable $A d r e v_{i, t}$ denotes annual advertising revenues of the $i$ th video website in the $t$ th year. This variable describes the performance of China's OTT service providers for the following reasons. Less than $10 \%$ of China's online video audience members had paid for Internet video content by the end of 2013, and advertising revenues are the major source of revenues for China's OTT service providers [63]. Furthermore, China's OTT service providers are undergoing a period of market expansion, and most of them are still unprofitable. Profitability is, therefore, not a feasible measure of the success of China's OTT service providers.

The independent variable Coverage $^{2}, t$ measures the square of the installed base of the $i$ th video website in the $t$ th year. The variable $P V_{i, t}$ denotes the average number of daily page views per viewer on the $i$ th video website in the $t$ th year. The success of a platform can be driven by the installed base or by the use of the platform [69]. In the context of China's OTT service providers, the installed base is represented by the variable Coverage ${ }^{2}{ }_{i, t}$, and the variable $P V_{i, t}$ captures the use of a platform [69]. The variable $U G C_{i, t}$ measures whether or not the $i$ th video website supports UGC uploading in the $t$ th year. The variable Mobile $e_{i, t}$ measures whether or not the percentage of viewers using mobile devices exceeds $25 \%$ of the total for the $i$ th video website in the $t$ th year. Mobile $e_{i, t}$ is a dichotomous variable that captures the effect of the ratio of an OTT service provider's mobile viewership on advertising revenues.

The study controls for platform and sectoral characteristics. The control variable $A g e_{i, t}$ measures the number of years since the establishment of the $i$ th OTT service provider by the $t$ th year. The control variable Internetpen $t_{t}$ measures the Internet penetration in the $t$ th year. This paper controls for different resources and capabilities that may affect performance by including website dummies as proxies for unobserved differences. Table 3 summarizes the statistics and correlations of key variables.

The authors have checked for potential problems of multicollinearity by calculating the VIF. Individual VIF values greater than 10 indicate a problem of multicollinearity [68], along with average VIF values greater than six. Although some correlation coefficients have moderate values, the individual VIF values (under 2.25) and the average VIF value (1.63) are at acceptable levels. Consequently, no problems of multicollinearity exist.

Table 3. Descriptive statistics and correlations of variables for OTT service providers.

\begin{tabular}{lcccccccccc}
\hline & Mean & SD & Min & Max & $\mathbf{1}$ & $\mathbf{2}$ & $\mathbf{3}$ & $\mathbf{4}$ & $\mathbf{5}$ & $\mathbf{6}$ \\
\hline 1. LnCoverage & 8.79 & 0.69 & 7.17 & 10.25 & 1.00 & & & & & \\
2. LnPV & 7.16 & 1.19 & 4.66 & 9.51 & 0.03 & 1.00 & & & & \\
3. UGC & 0.51 & 0.50 & 0.00 & 1.00 & 0.11 & 0.17 & 1.00 & & & \\
4. Mobile & 0.55 & 0.50 & 0.00 & 1.00 & 0.54 & -0.12 & -0.02 & 1.00 & & \\
5. Age & 5.82 & 1.62 & 1 & 8 & 0.24 & 0.17 & 0.39 & 0.35 & 1.00 & \\
6. Internetpen (\%) & 42.06 & 3.09 & 38.30 & 45.80 & 0.52 & -0.04 & 0.09 & 0.69 & 0.41 & 1.00 \\
\hline
\end{tabular}




\subsection{Methodology}

The data used are both cross-sectional and time series. The use of panel data helps to control for potential sources of unobserved heterogeneity [70,71]. These data, however, often present problems of heteroscedasticity and first-order autocorrelation [72,73]. Indeed, testing of our data for the models for OTT service providers $(\mathrm{O})$ and cable operators $(\mathrm{C})$ revealed both heteroscedasticity (Wald tests: $(\mathrm{O})$ $\left.\operatorname{chi2}(17)=1.9 \times 10^{5}, p>0.00 ;(\mathrm{C}) \operatorname{chi} 2(24)=10,583.8, p>0.00\right)$ and autocorrelation errors (Wooldridge tests: $(\mathrm{O}) \mathrm{F}(1,16)=41.09, p>0.0154 ;(\mathrm{C}) \mathrm{F}(1,23)=17.93, p>0.0027)$. Heteroscedasticity and autocorrelation problems violate conventional suppositions for analysis with ordinary least squares and cause the estimations to be biased. To address these problems, panel-correlated standard errors (PCSE) can be useful [74]. Thus, the PCSE method was employed in this study to estimate the models.

It is also necessary to test whether or not the models have individual effects (both cross-section and period). As shown in Tables 4 and 5, the results of redundant fixed effect tests reject the null hypothesis that the cross-section effects are zero, and accept the null hypothesis that the period effects are zero. There is then a choice between the fixed effect models and the random effect models. Low probabilities of the Hausman test for all six models indicate that the null hypothesis that random effects are more appropriate should be rejected. Finally, all six models are estimated with entity-specific fixed effects.

Table 4. Regression results of cable operators.

\begin{tabular}{|c|c|c|c|}
\hline & Model 1 & Model 2 & Model 3 \\
\hline Digcov & & $\begin{array}{l}0.208^{* * *} \\
(8.883)\end{array}$ & $\begin{array}{l}-0.172 * * * \\
(-1.911)\end{array}$ \\
\hline Paycov & & $\begin{array}{l}0.084^{* * *} \\
(6.407)\end{array}$ & $\begin{array}{l}0.092^{* * * *} \\
(7.460)\end{array}$ \\
\hline Numchan & & $\begin{array}{l}0.104^{* *} \\
(2.220)\end{array}$ & $\begin{array}{l}-1.568^{* * * *} \\
(-4.166)\end{array}$ \\
\hline Netlen & $\begin{array}{c}0.064 \\
(-1.197)\end{array}$ & $\begin{array}{c}-0.060 \\
(-1.197)\end{array}$ & $\begin{array}{c}-0.038 \\
(-0.877)\end{array}$ \\
\hline View & $\begin{array}{c}0.147 * \\
(-2.121)\end{array}$ & $\begin{array}{l}-0.250 * * \\
(-2.121)\end{array}$ & $\begin{array}{l}-0.471^{* * * *} \\
(-2.974)\end{array}$ \\
\hline Broadpen & $\begin{array}{l}0.798^{* * *} \\
(6.194)\end{array}$ & $\begin{array}{l}0.263^{* * *} \\
(6.194)\end{array}$ & $\begin{array}{l}0.235^{* * *} \\
(5.071)\end{array}$ \\
\hline Numchan $\times$ Digcov & & & $\begin{array}{l}0.113^{* * *} \\
(4.458)\end{array}$ \\
\hline Regional dummies & Yes & Yes & Yes \\
\hline$R^{2}$ adjusted & 0.942 & 0.961 & 0.963 \\
\hline $\begin{array}{l}\text { Redundant Fixed Effects Tests } \\
\text { Cross-section F (Prob.) }\end{array}$ & $\begin{array}{l}58.091 \\
(0.000)\end{array}$ & $\begin{array}{l}36.016 \\
(0.000)\end{array}$ & $\begin{array}{l}43.010 \\
(0.000)\end{array}$ \\
\hline Period F (Prob.) & $\begin{array}{c}3.458 \\
(0.052) \\
\end{array}$ & $\begin{array}{c}2.179 \\
(0.060)\end{array}$ & $\begin{array}{c}2.034 \\
(0.078)\end{array}$ \\
\hline Hausman test prob. & 0.001 & 0.001 & 0.000 \\
\hline
\end{tabular}

Notes: $*, \overline{* *},{ }^{* * *}$ represents significant levels of $10 \%, 5 \%$, and $1 \%$, respectively, and the value in the parenthesis represents $t$ statistics. 
Table 5. Regression results for OTT service providers.

\begin{tabular}{|c|c|c|c|}
\hline & Model 4 & Model 5 & Model 6 \\
\hline Coverage $^{2}$ & & $\begin{array}{l}0.095^{* * *} \\
(6.965)\end{array}$ & $\begin{array}{l}0.118^{* *} \\
(3.690)\end{array}$ \\
\hline$P V$ & & $\begin{array}{l}-0.227^{* * * *} \\
(-4.622)\end{array}$ & $\begin{array}{l}-0.198 * * \\
(-2.667)\end{array}$ \\
\hline UGC & & $\begin{array}{l}0.299 * * * \\
(13.347)\end{array}$ & $\begin{array}{l}-4.486 * * * \\
(-3.248)\end{array}$ \\
\hline Mobile & & $\begin{array}{l}0.561 * * * \\
(22.011)\end{array}$ & $\begin{array}{l}0.498^{* * *} \\
(15.203)\end{array}$ \\
\hline UGC $\times$ Coverage & & & $\begin{array}{l}0.516 * * \\
(2.599)\end{array}$ \\
\hline$U G C \times P V$ & & & $\begin{array}{l}-0.048 \\
(-0.500)\end{array}$ \\
\hline Age & $\begin{array}{l}1.104^{* * *} \\
(11.498)\end{array}$ & $\begin{array}{l}0.870 * * * \\
(6.633)\end{array}$ & $\begin{array}{l}1.035^{* * *} \\
(5.054)\end{array}$ \\
\hline Internetpen & $\begin{array}{l}0.333^{* *} \\
(8.885)\end{array}$ & $\begin{array}{l}0.437 * \\
(1.883)\end{array}$ & $\begin{array}{c}-0.484 \\
(-0.763)\end{array}$ \\
\hline Website Dummies & Yes & Yes & Yes \\
\hline$R^{2}$ adjusted & 0.586 & 0.896 & 0.898 \\
\hline $\begin{array}{l}\text { Redundant Fixed Effects Tests } \\
\text { Cross-section F (Prob.) }\end{array}$ & $\begin{array}{l}59.291 \\
(0.000)\end{array}$ & $\begin{array}{l}30.266 \\
(0.000)\end{array}$ & $\begin{array}{l}10.157 \\
(0.000)\end{array}$ \\
\hline Period F (Prob.) & $\begin{array}{c}7.218 \\
(0.058)\end{array}$ & $\begin{array}{c}3.421 \\
(0.082)\end{array}$ & $\begin{array}{c}2.917 \\
(0.063) \\
\end{array}$ \\
\hline Hausman test prob. & 0.000 & 0.000 & 0.000 \\
\hline
\end{tabular}

Notes: $* * * * * *$ represents significant levels of $10 \%, 5 \%$, and $1 \%$, respectively, and the value in the parenthesis represents $t$ statistics.

\subsection{Results}

\subsubsection{Cable Operators}

The regression results for cable operators are given in Table 4. Model 1 is a baseline model, including all the control variables. Model 2 includes all the independent variables to test hypotheses $\mathrm{H} 1 \mathrm{a}, \mathrm{H} 1 \mathrm{~b}$, and H2. Model 3 adds an interaction term to test H7. For control variables, Broadpen is significantly positively correlated with Netrev, which means that revenues from cable network operation increases with broadband penetration. The coefficient of View is significant and positive. This indicates that viewers' TV watching time exerts a positive impact on cable operators' revenues. The control variable Netlen has an insignificantly negative impact on Netrev.

In Model 2, Digcov has a significant and positive impact on Netrev. This means that revenues from network operation increase when more households subscribe to digital TV services, which is in line with previous empirical findings [43]. Paycov has a significantly positive, but relatively small, impact on revenues from network operation. It shows a minor role played by pay TV in revenue contribution. The impact of Numchan is significantly positive. In fact, Chinese audiences perceive the larger number of channels as one of the major benefits of the transition to digital TV [43]. Consequently, Hypotheses H1a, H1b, and H2 are supported. In Model 3, the coefficient of interaction term Numchan $\times$ Digcov is significant and positive. It demonstrates that the amount of TV channels and digital TV coverage may be complementary in terms of revenue contribution, thus supporting H7. 


\subsubsection{OTT Service Providers}

The regression results for OTT service providers are given in Table 5. Model 4 is a baseline model, including all the control variables. Model 5 includes all the independent variables to test hypotheses H3, H4, H5, and H6. Model 6 adds interaction terms to test H8a and H8b. The signs of the control variables are in line with the authors' expectations. The positive sign of Age demonstrates that staying in the market longer can lead to better performance in China's online video industry. The positive sign of Internetpen indicates that OTT service providers, as a whole, benefit from the rising penetration of the Internet in the country.

In Model 5, the results show that Coverage $^{2}$ has a significant and positive impact on the performance of OTT service providers. It demonstrates the existence of network effects in China's online video platforms. The impact of $P V$ on advertising revenues is significantly negative. Actually, $P V$ can produce opposite effects. On one hand, the larger the number of page views, the more advertisers are willing to pay. On the other hand, the higher the views, the more experienced viewers become, which may lead to advertisement avoidance, for example, through advertisement blocking apps [75]. UGC has a significantly positive impact on advertising revenues. This highlights the function of UGC for OTT service providers, which generally lack content in comparison with the traditional TV sector [76]. Consequently, $\mathrm{H} 3$ and $\mathrm{H} 5$ are supported, and $\mathrm{H} 4$ is not supported. The impact of Mobile on advertising revenues is significantly positive, thus supporting H6. In Model 6, the coefficient of the interaction between UGC and Coverage is significant and positive. It may indicate that UGC and Coverage are complementary, thus supporting H8a. The coefficient of the interaction between UGC and $P V$ is negative and insignificant, thus, not supporting $\mathrm{H} 8 \mathrm{~b}$.

\subsection{Discussion}

The installed base (Coverage ${ }^{2}$ for OTT service providers and Digcov for cable operators) plays an important role in the performance of both OTT service providers and cable operators. This confirms previous findings that the installed base can be a resource of competitive advantage in the video industry [14]. However, the role of viewers is different between China's OTT service providers and cable operators. Digital cable TV has allowed viewers to have more freedom to watch TV, that is, to choose any content at any time. Beyond such freedom, online platforms allow and encourage interaction among viewers. The impact of Coverage $^{2}$ on the performance of OTT service providers demonstrates that online platforms can benefit from interaction on the demand side. In this way, online platforms provide viewers with the social experience of content consumption based on virtual communities. Further, OTT service providers can create and capture new value by designing a business model to exploit the emerging demand-side linkage. This finding verifies that firms should attach importance to customer-related resources and capabilities when designing digital business strategies in the era of digital convergence [38].

On a multi-sided platform, the number of users may have a positive impact on value for advertisers. However, emerging papers claim to open the black box of an installed base [9,53]. Thus, it is important to analyze different characteristics of the installed base, such as use [69]. For OTT service providers, the significant negative effect of $P V$ on performance confirms that not only the number of users, but also their behaviour, is important. This is coherent with recent insights into the negative attitudes of youngsters towards Internet advertising [75]. In addition, the authors argue that how a platform is used is as important as the time length of platform use. UGC, which can actually be regarded as a form of platform engagement and contribution, produces a significant and positive impact. Paycov, which includes interactive TV and, therefore, can be partially regarded as a form of platform engagement in the traditional TV sector, is proved to have a positive impact on performance. The above findings imply that both OTT service providers and cable operators should spare no efforts to promote new-type platform use in the future.

The significant positive impact of Numchan on the performance of cable operators demonstrates that quality improvement on the supply side of a platform can contribute to platform performance. 
The digital switchover has enabled cable operators to provide better service and quality content for viewers. Quality content is one of the advantages of China's traditional TV sector over OTT service providers. The traditional sector should therefore give full play to its quality content or service, allowing viewers to watch their favourite content anytime, anywhere. For example, China's cable operators should launch online streaming video to meet viewer demand, as US-based Comcast has offered Xfinity Apps.

The significantly positive impact of Mobile on the advertising revenues of OTT service providers demonstrates that the multi-screen strategy is effective in China's converging video industry. This finding supports previous insights that a seamless viewing experience can create value for viewers and advertisers in the era of digital convergence [16]. The multi-screen strategy enables OTT service providers to consolidate their customer relationships and to better act as intermediary among content providers, audiences, and advertisers. With the rising penetration of mobile devices in China, the authors speculate that the multi-screen strategy will play an increasingly important role in the era of digital convergence.

The role of interaction terms is different across players. The significantly positive impact of UGC $\times$ Coverage may highlight the complementary interaction between UGC and viewership. With more UGC, a video website not only can solve the problem of content scarcity, but also improve its performance without expanding the size of its installed base. UGC is especially important for China's OTT service providers to attract and retain viewers. These OTT service providers lack the resources and capabilities to produce or purchase professional content. UGC helps the online platforms to turn some consumers into producers. Multiple roles (viewers, producer, reviewer, and curator) can produce positive feedback and the online platform can take advantage. The positive impact of the interaction term of cable operators may demonstrate that cable operators can benefit from coordination between the demand side and the supply side. China's digital switchover has coincided with increase in the penetration of digital cable TV and the number of average channels received by digital TV. This shows that cable operators, as platform owners, have successfully enhanced the platform adoption by the two sides. However, the growth has gradually slowed as the market has become saturated. This means that China's cable operators will need to move their business focus from user scale to contribution per user. This result suggests some further implication for recent research on the weaknesses of traditional TV firms attempting to exploit cross-side externalities between content and viewers [14].

\section{Conclusions and Implications}

This paper explores the determinants of firm performance in China's video industry in the era of digital convergence. Adopting the perspective of an industry platform, this paper theoretically analyzes two potential industry platforms in the industry-cable operators and OTT service providers. In this way, we contribute to the understanding of industry platforms in a specific context. Further, this paper empirically investigates what factors have impacts on the performance of the two market players. We contribute to the literature on convergence by explaining different key factors besides installed base. In this respect, we show that the users are taking a more active role and it is becoming critical for platform owners to strategically manage the interactions with them.

This research has managerial implications for firms in converging industries. Industry convergence is turning related industries into an ecosystem of businesses [77], where an industry platform can play a core role. This paper highlights the role of both the installed base and platform engagement for any firm that desires to become an industry platform. Drawing experience from players in China's converging video industry, firms can facilitate platform use by leveraging innovations by complementary parties or establishing a social community of end users. For players in the video industry, digital technologies not only represent the upgrade from analog video to digital video, but also enable firms to redesign their business models to co-create value with their partners. Firms with the ability to explore and exploit interdependence within the ecosystem may have competitive advantage 
in the era of digital convergence. In this sense, OTT service providers seem to have the capability of facilitating and managing close relationships among a large number of users. Meanwhile, cable operators are starting to find complementarities between agents on their platforms.

The findings of this paper also have implications for the regulators of converging industries. The strategy of a platform owner may have regulatory implications in the following two ways. First, the strategy may be subject to regulation, including the pricing and $\mathrm{M}$ and A strategies of a platform owner [23]. Second, a platform owner can act as a regulator of its platform ecosystem via information, contractual and technical instruments [27]. The strategies of a platform owner may have a direct regulatory effect within its ecosystem. For example, platform openness is one of important decisions for a platform owner, and it is not only a strategic decision but also a regulatory policy. How to coordinate internal regulation with external regulation poses a challenge for regulators. The findings regarding performance determinants could help regulators develop a normative framework to enhance the ability of different types of agents to exploit the potential of digital technologies. For example, Chinese regulators may develop norms that help traditional firms interact more easily with viewers. Furthermore, it is the regulators' responsibility to create a level playing field for both entrants and incumbents and to identify the emergence of an industry platform. China's OTT service providers, as new market entrants, are subject to more relaxed regulations on both content and business operation than firms in the traditional TV sector. With heterogeneous and substitutable solutions, the OTT service providers have risen as a potential industry platform. An industry platform that possesses a hub position in an ecosystem of businesses, however, actually deserves more attention and supervision from regulators.

This paper has some limitations that may inspire future research. First, the data used in this paper are limited to the beginning of industry convergence. Future research could analyze the evolution of the drivers and the performance at a more mature stage of industry convergence. Second, this paper explores the research question in the context of China's video industry. Theoretical and empirical research on the determinants of business performance in the era of digital convergence in different countries may provide valuable findings on how cultural and institutional characteristics may moderate their effects and add new drivers. Third, the performance of OTT service providers or cable operators is also influenced by external factors such as the legal framework, regulatory policies, and market structure. Future research can probe these factors independently or investigate how these factors interact with the demand or supply side of these potential industry platforms. Fourth, the power of an industry platform lies in the fact that it can facilitate value co-creation and coordinate value capture. This paper has not yet empirically explored the issue of value co-creation and capture. Along these lines, adding variables representing cooperation and competition could deepen our understanding of value co-creation and capture in the era of digital convergence.

Acknowledgments: The authors appreciate all the helpful and insightful comments of anonymous reviewers and editors. The authors owe their thanks for the financial support provided by the National Social Science Foundation of China (Grant No. 17BGL200), the National Science Foundation of China (Grant Nos. 71671081 and 71331004), and the Natural Sciences and Engineering Research Council of Canada (Grant No. 372400), and the Humanities and Social Science Project of Ministry of Education (Grant No. 15YJA630065).

Author Contributions: Xing Wan conceived the aim of the paper, conducted the data collection, and executed the analysis. Javier Cenamor contributed to the theoretical background and assisted in the examination of the results. Jing Chen contributed to the empirical analysis and revised the manuscript.

Conflicts of Interest: The authors declare no conflict of interest. The founding sponsors had no role in the design of the study; in the collection, analyses, or interpretations of data; in the writing of the manuscript; or in the decision to publish the results. 


\section{References}

1. Hacklin, F. Management of Convergence in Innovation: Strategies and Capabilities for Value Creation beyond Blurring Industry Boundaries; Physica-Verlag: Heidelberg, Germany, 2007.

2. Wan, X.; Xuan, Y.; Lv, K. Measuring convergence of China's ICT industry: An input-output analysis. Telecommun. Policy 2011, 35, 301-313. [CrossRef]

3. Doyle, G. Digitization and changing windowing strategies in the television industry: Negotiating new windows on the world. Telev. New Media 2016, 17, 629-645. [CrossRef]

4. Shin, J.; Park, Y.; Lee, D. Google TV or apple TV?-The reasons for smart TV failure and a user-centered strategy for the success of smart TV. Sustainability 2015, 7, 15955-15966. [CrossRef]

5. D'Aveni, R.A.; Dagnino, G.B.; Smith, K.G. The age of temporary advantage. Strateg. Manag. J. 2010, 31, 1371-1385. [CrossRef]

6. Den Hartigh, E.; Ortt, J.R.; van de Kaa, G.; Stolwijk, C.C.M. Platform control during battles for market dominance: The case of apple versus IBM in the early personal computer industry. Technovation 2016, 48-49, 4-12. [CrossRef]

7. Gallagher, S.R. The battle of the blue laser DVDs: The significance of corporate strategy in standards battles. Technovation 2012, 32, 90-98. [CrossRef]

8. Suarez, F.F. Battles for technological dominance: An integrative framework. Res. Policy 2004, 33, $271-286$. [CrossRef]

9. Cenamor, J.; Usero, B.; Fernández, Z. The role of complementary products on platform adoption: Evidence from the video console market. Technovation 2013, 33, 405-416. [CrossRef]

10. Gawer, A.; Cusumano, M.A. Industry platforms and ecosystem innovation. J. Prod. Innov. Manag. 2014, 31, 417-433. [CrossRef]

11. Thomas, L.W.; Autio, E.; Gann, D.M. Architectural leverage: Putting platforms in context. Acad. Manag. Perspect. 2014, 28, 198-219. [CrossRef]

12. Wirtz, B.W. Reconfiguration of value chains in converging media and communications markets. Long Range Plan. 2001, 34, 489-506. [CrossRef]

13. Funk, J.L. The emerging value network in the mobile phone industry: The case of Japan and its implications for the rest of the world. Telecommun. Policy 2009, 33, 4-18. [CrossRef]

14. Evens, T. Platform leadership in online broadcasting markets. In Handbook of Social Media Management; Springer: Berlin/Heidelberg, Germany, 2013; pp. 477-491.

15. Wu, I. Canada, South Korea, Netherlands and Sweden: Regulatory implications of the convergence of telecommunications, broadcasting and Internet services. Telecommun. Policy 2004, 28, 79-96. [CrossRef]

16. Lin, T.T.C. Convergence and regulation of multi-screen television: The Singapore experience. Telecommun. Policy 2013, 37, 673-685. [CrossRef]

17. Wu, R.W.S.; Leung, G.L.K. Implementation of three network convergence in China: A new institutional analysis. Telecommun. Policy 2012, 36, 955-965. [CrossRef]

18. Curran, C.-S.; Bröring, S.; Leker, J. Anticipating converging industries using publicly available data. Technol. Forecast. Soc. Chang. 2010, 77, 385-395. [CrossRef]

19. Yoo, Y.; Boland, R.J.; Lyytinen, K.; Majchrzak, A. Organizing for innovation in the digitized world. Organ. Sci. 2012, 23, 1398-1408. [CrossRef]

20. Hacklin, F.; Battistini, B.; von Krogh, G. Strategic choices in converging industries. MIT Sloan Manag. Rev. 2013, 55, 65-73.

21. Li, S.-C.S. Market competition and the media performance of Taiwan's cable television industry. J. Media Econ. 2004, 17, 279-294. [CrossRef]

22. Gawer, A.; Cusumano, M.A. How companies become platform leaders. MIT Sloan Manag. Rev. 2008, 49, $28-35$.

23. Wan, X.; Cenamor, J.; Parker, G.; Van Alstyne, M. Unraveling platform strategies: A review from an organizational ambidexterity perspective. Sustainability 2017, 9, 734. [CrossRef]

24. Urgelles, A. The threat of ott for the pay TV market. In Current and Emerging Issues in the Audiovisual Industry; Medina, M., Herrero, M., Urgellés, A., Eds.; ISTE Ltd./John Wiley \& Sons: Hoboken, NJ, USA, 2017.

25. Srnicek, N. Platform Capitalism; John Wiley \& Sons: Hoboken, NJ, USA, 2016. 
26. Tiwana, A.; Konsynski, B.; Bush, A.A. Research commentary: Platform evolution: Coevolution of platform architecture, governance, and environmental dynamics. Inf. Syst. Res. 2010, 21, 675-687. [CrossRef]

27. Boudreau, K.J.; Hagiu, A. Platform rules: Multi-sided platforms as regulators. In Platforms, Markets and Innovation; Gawer, A., Ed.; Edward Elgar Publishing: Northampton, MA, USA, 2009; pp. 163-191.

28. Sridhar, S.; Mantrala, M.K.; Naik, P.A.; Thorson, E. Dynamic marketing budgeting for platform firms: Theory, evidence, and application. J. Mark. Res. 2011, 48, 929-943. [CrossRef]

29. Boudreau, K. Let a thousand flowers bloom? An early look at large numbers of software app developers and patterns of innovation. Organ. Sci. 2012, 23, 1409-1427. [CrossRef]

30. Chaturvedi, A.R.; Dolk, D.R.; Drnevich, P.L. Design principles for virtual worlds. MIS Q. 2011, 35, 673-684. [CrossRef]

31. Jeppesen, L.B.; Frederiksen, L. Why do users contribute to firm-hosted user communities? The case of computer-controlled music instruments. Organ. Sci. 2006, 17, 45-63. [CrossRef]

32. Eisenmann, T.; Parker, G.; Van Alstyne, M. Strategies for two-sided markets. Harv. Bus. Rev. 2006, 84, 92-101.

33. Roson, R. Two-sided markets a tentative survey. Rev. Netw. Econ. 2005, 4, 142-160. [CrossRef]

34. Rysman, M. The economics of two-sided markets. J. Econ. Perspect. 2009, 23, 125-143. [CrossRef]

35. Rochet, J.C.; Tirole, J. Platform competition in twotwoor two-sided. J. Eur. Econ. Assoc. 2003, 1, 990-1029. [CrossRef]

36. Bhargava, H.K.; Choudhary, V. Economics of an information intermediary with aggregation benefits. Inf. Syst. Res. 2004, 15, 22-36. [CrossRef]

37. Kauffman, R.J.; Hamid, M. Proprietary and open systems adoption in e-procurement. J. Manag. Inf. Syst. 2004, 21, 137-166. [CrossRef]

38. Oestreicher-Singer, G.; Zalmanson, L. Content or community? A digital business strategy for content providers in the social age. MIS Q. 2013, 37, 591-616. [CrossRef]

39. DaSilva, C.M.; Trkman, P. Business model: What it is and what it is not. Long Range Plan. 2014, 47, 379-389. [CrossRef]

40. Song, M. A study of media business innovation of Korea telecom. Int. J. u- e-Serv. Sci. Technol. 2016, 9, 249-264. [CrossRef]

41. Suarez, F.F.; Kirtley, J. Dethroning an established platform. MIT Sloan Manag. Rev. 2012, 53, 35-40.

42. Eisenmann, T.; Parker, G.; Van Alstyne, M. Platform envelopment. Strateg. Manag. J. 2011, 32, $1270-1285$. [CrossRef]

43. Wan, X.; Hu, H.H.; Wu, C. A theoretical and empirical study on China's transition to digital TV. Telecommun. Policy 2009, 33, 653-663.

44. Slot, M. Changing user roles in ict developments; the case of digital television. Telemat. Inf. 2007, 24, 303-314. [CrossRef]

45. Mayo, J.W.; Otsuka, Y. Demand, pricing, and regulation: Evidence from the cable TV industry. RAND J. Econ. 1991, 22, 396-410. [CrossRef]

46. Otsuka, Y. A welfare analysis of local franchise and other types of regulation: Evidence from the cable TV industry. J. Regul. Econ. 1997, 11, 157-180. [CrossRef]

47. Chipty, T. Vertical integration, market foreclosure, and consumer welfare in the cable television industry. Am. Econ. Rev. 2001, 91, 428-453. [CrossRef]

48. Gupta, S.; Mela, C.F. What is a free customer worth? Armchair calculations of nonpaying customers' value can lead to flawed strategies. Harv. Bus. Rev. 2008, 86, 102-109. [PubMed]

49. Armstrong, M. Competition in two-sided Markets. RAND J. Econ. 2006, 37, 668-691. [CrossRef]

50. Rochet, J.-C.; Tirole, J. Cooperation among competitors: Some economics of payment card associations. RAND J. Econ. 2002, 33, 549-570. [CrossRef]

51. Kaiser, U.; Wright, J. Price structure in two-sided markets: Evidence from the magazine industry. Int. J. Ind. Organ. 2006, 24, 1-28. [CrossRef]

52. Gal-or, E.; Geylani, T.; Yildirim, T.P. The impact of advertising on media bias. J. Mark. Res. 2012, 49, 92-99. [CrossRef]

53. Afuah, A. Are network effects really all about size? The role of structure and conduct. Strateg. Manag. J. 2013, 34, 257-273. [CrossRef]

54. Cusumano, M.A. Platform wars come to social media. Commun. ACM 2011, 54, 31-34. [CrossRef] 
55. Lai, L.S.L.; Turban, E. Groups formation and operations in the web 2.0 environment and social networks. Group Decis. Negotiat. 2008, 17, 387-402. [CrossRef]

56. Hacklin, F.; Marxt, C.; Fahrni, F. Coevolutionary cycles of convergence: An extrapolation from the ICT industry. Technol. Forecast. Soc. Chang. 2009, 76, 723-736. [CrossRef]

57. Liu, X. Platform Competition in the Online Video Industry: A Comparison between the United States and Chinese Markets. Master's Thesis, Massachusetts Institute of Technology, Cambridge, CA, USA, 2013.

58. Bogers, M.; Afuah, A.; Bastian, B. Users as innovators: A review, critique, and future research directions. J. Manag. 2010, 36, 857-875. [CrossRef]

59. Pon, B.; Seppälä, T.; Kenney, M. One ring to unite them all: Convergence, the smartphone, and the cloud. J. Ind. Compet. Trade 2015, 15, 21-33. [CrossRef]

60. Peitz, M.; Valletti, T.M. Content and advertising in the media: Pay-TV versus free-to-air. Int. J. Ind. Organ. 2008, 26, 949-965. [CrossRef]

61. Gawer, A. Platforms, Markets and Innovation; Edward Elgar Publishing: Northampton, MA, USA, 2009.

62. El Sawy, O.A. The is core IX: The 3 faces of is identity: Connection, immersion, and fusion. Commun. Assoc. Inf. Syst. 2003, 12, 588-598.

63. China Internet Network Information Center. Research Report on Online Video Consumption by Chinese Netizens; CNNIC: Beijing, China, 2013.

64. China Internet Network Information Center. The Statistical Report on China's Internet Development; CNNIC: Beijing, China, 2017.

65. Liu, C. Examining China's triple-network convergence plan: Regulatory challenges and policy recommendations. Gov. Inf. Q. 2013, 30, 45-55. [CrossRef]

66. Mangold, W.G.; Faulds, D.J. Social media: The new hybrid element of the promotion mix. Bus. Horiz. 2009, 52, 357-365. [CrossRef]

67. Haridakis, P.; Hanson, G. Social interaction and co-viewing with YouTube: Blending mass communication reception and social connection. J. Broadcast. Electron. Media 2009, 53, 317-335. [CrossRef]

68. Neter, J.; Wasserman, W.; Kutner, M.H. Applied Regression Models; Irwin: Homewood, IL, USA, 1989.

69. Lanzolla, G.; Suarez, F.F. Closing the technology adoption-use divide the role of contiguous user bandwagon. J. Manag. 2012, 38, 836-859. [CrossRef]

70. Adner, R.; Kapoor, R. Value creation in innovation ecosystems: How the structure of technological interdependence affects firm performance in new technology generations. Strateg. Manag. J. 2010, 31, 306-333. [CrossRef]

71. Afuah, A. Mapping technological capabilities into product markets and competitive advantage: The case of cholesterol drugs. Strateg. Manag. J. 2002, 23, 171-179. [CrossRef]

72. Strang, D. Adding social structure to diffusion models an event history framework. Sociol. Methods Res. 1991, 19, 324-353. [CrossRef]

73. Van den Bulte, C.; Stremersch, S. Social contagion and income heterogeneity in new product diffusion: A meta-analytic test. Mark. Sci. 2004, 23, 530-544. [CrossRef]

74. Beck, N.; Katz, J.N. What to do (and not to do) with time-series cross-section data. Am. Political Sci. Rev. 1995, 89, 634-647. [CrossRef]

75. Logan, K. Hulu.com or NBC? Streaming video versus traditional TV. J. Advert. Res. 2011, 51, $276-287$. [CrossRef]

76. Kim, J. The institutionalization of youtube: From user-generated content to professionally generated content. Media Cult. Soc. 2012, 34, 53-67. [CrossRef]

77. Zhang, J.; Liang, X.-J. Business ecosystem strategies of mobile network operators in the 3G era: The case of china mobile. Telecommun. Policy 2011, 35, 156-171. [CrossRef]

(C) 2017 by the authors. Licensee MDPI, Basel, Switzerland. This article is an open access article distributed under the terms and conditions of the Creative Commons Attribution (CC BY) license (http:/ / creativecommons.org/licenses/by/4.0/). 